extended right hepatic resection in small-for-size settings. Annals of surgery, 255(3), 405-414.

8. Le Roy B., Dupré A., Gallon A. và công sự. (2018). Liver hypertrophy: Underlying mechanisms and promoting procedures before major hepatectomy. Journal of visceral surgery, 155(5), 393-401.

9. Lê Thanh Dũng (2018), Nghiên cứu áp dụng và đánh giá hiệu quả của phương pháp nút nhánh tĩnh mạch cửa gây phì đại gan trước phẩu thuật cắt gan, Luận án Tiến sĩ Y học, Đại học Y Hà Nội.

\title{
ĐÁNH GIÁ Độ CHÍNH XÁC VÀ AN TOÀN CỦA KỸ THUÂT TIÊM NGOÀI MÀNG CỨNG CộT SỐNG THẮT LƯNG DƯỚI HƯỚNG DẪN CỦA SIÊU ÂM
}

\section{TÓM TẮT}

Mục tiêu: bước đầu đánh giá độ chính xác và an toàn của phương pháp tiêm steroid ngoài màng cứng qua lỗ liên hợp bằng cách xác thực dưới $x$ quang. Phương pháp: nghiên cứu mô tả 15 người bênh, đau kiểu rễ thần kinh do thoát vị đĩa đệm cột sống thắt lưng, được tiến hành tiêm steroid ngoài màng cứng qua lỗ liển hợp với kim được dẫn đường dưới hướng dẫn của siêu âm trên bình diện cắt ngang của cột sống và được xác thực bằng chụp x quang. Kết quả: độ chính xác của can thiệp dưới hướng dân của siêu âm là 86,7\% được xác thực bởi chụp x quang. Có 02 trường hợp không chính xác: 01trường hợp sai tâng và 01 trường hợp đúng tầng nhưng kim ở ngoài lố liên hợp. Không có biến chứng nào được ghi nhận. Kết luận: Tiêm ngoài màng cứng qua lố liên hợp là chính xác và có thế thực hiện trong lâm sàng với độ chính xác bước đâuu là $86,7 \%$ và không có biến chứng.

Tư khóa: Tiêm ngoài màng cứng, đau thắt lưng, đau kiểu rễ thần kinh, thoát vị đĩa đệm, siêu âm

\section{SUMMARY}

\section{THE ACCURACY AND SAFETY OF ULTRASOUND - GUIDED LUMBAR TRANSFORAMINAL EPIDURAL INJECTION}

Objective: To investigate the accuracy and safety rate (technical precision) of ultrasound-guided lumbar transforaminal epidural steroid injection, which was validated by conventional fluoroscopic technique. Methods: A total of 15 patients with unilateral singlelevel lumbar foraminal disc protrusion causing radiculopathy were enrolled. Using transforming route, the needle location was determined by an axial (transvers) view of the ultrasound with fluoroscopic confirmation. Results: The accuracy of ultrasoundguided interventions was $86,7 \%$ as confirmed by fluoroscopy. There were 02 failed cases in the USguided: 01 case were wrong level and 01 case was right level but in extraforaminal. No complications

*Bệnh viện HN Việt Đức

Chịu trách nhiệm chính: Nguyễn Hoàng Long

Email: longnguyen.drspine@gmail.com

Ngày nhận bài: 5.8.2021

Ngày phản biên khoa họ: 5.10 .2021

Ngày duyệt bài: 14.10.2021

\section{Nguyễn Hoàng Long*, Vũ Văn CườngB*, Nguyễn Duy Linh*, Lê Đức Anh*}

were noted. Conclusion: Ultrasound-guided lumbar transforaminal epidural injections are accurate and feasible in clinical setting with an accuracy of $86,7 \%$ and no complications.

Key word: Epidural injection, low back pain, radiculopathy, disc herniation, ultrasound

\section{I. ĐẶT VẤN ĐỀ}

Đau kiểu rễ thần kinh cột sống thắt lưng thường do nguyên nhân chèn ép hoặc kích thích các rễ thân kinh tương ứng trong ống sông hoặc trên đường đi của rễ. Các phương pháp điêuu trị từ bảo tôn cho tới phẫu thuật.Phong bế ngoài màng cứng (NMC) qua lỗ liên hợp là thủ thuật hay được dùng điều trị đau lan kiểu rễ thân kinh do nguyên nhân từ cột sống[1]. Thông thường thủ thuật này sẽ được thực hiện dưới hướng dẫn của X-quang hoặc cắt lớp vi tính vì có thể quan sát đâu mũi kim và sự lan thuốc cản quang. Tuy nhiên, nhược điểm chính của thủ thuật này là nguy cơ nhiễm tia chongười bệnh(NB), bác sĩ và các nhân viên y tế khác, yêu cầu có khu vực đặc biệt (buông có bọc chì, tấm chắn tia $X$, bàn làm thủ thuật cần thấu quang...) để thực hiện những thủ thuật này, trang thiết bị đắt tiền, mặc đồ bảo hộ nặng, nóng và không thoải mái.Trong vài năm gần đây, tiêm phong bế thần kinh dưới hướng dẫn của siêu âm được áp dụng cho thấyđã khắc phục được những nhược điểm nói trên của phương pháp phong bế dưới hướng dẫn của $x$ quang và cắt lớp vi tính. Mặc dù siêu âm được chứng minh là an toàn và khả thi đối với tiêm cột sống như tiêm phong bế rễ thân kinh, phong bế nhánh trong, và tiêm diện khớp, nhưng đối với phương pháp tiêm NMC qua lỗ liên hợp vẫn còn những thách thức vì bóng cản của các cấu trúc xương ở khu vực lỗ liên hợpvì vậy gây khó khăn cho sự quan sát đâu kim ở vị trí này.

Ở Việt Nam, phương pháp tiêm NMC qua lỗ liên hợp dưới hướng dấn của $X$ quang đã được tiến hành ở một số trung tâm như bệnh viện HN Việt Đức, bệnh viện trung ương Đà Nẵng ... Còn 
phương pháp gây tê NMC qua lỗ liên hợp dưới hướng dân của siêu âm tuy đã có một số trung tâm ứng dụng phương pháp này trong thực hành lâm sàng, tuy nhiên chưa có báo cáo cho thây tính chính xác và an toàn của phương pháp.

\section{II. ĐỐI TƯợNG VÀ PHƯƠNG PHÁP NGHIÊN CứU}

2.1 Đối tượng nghiên cứu: Người bệnh được chẩn đoán đau kiểu rễ do thoát vị đĩa đêm/phình đĩa đêm cột sống thắt lưng, được chỉ định tiêm ngoài màng cứng tại khoa Phẫu thuật cột sống bệnh viện HN Việt Đức từ tháng 5/2021 đến tháng 8/2021, thỏa mãn tiêu chuẩn nghiên cứu.

Tiêu chuẩn lựa chọn người bệnh: Người bệnh được chẩn đoán thoát vị đĩa đệm cột sống thắt lưng với triệu chứng đau lan kiểu rễ dây thần kinh tương ứng với thoát vị được xác định trên phim chụp cộng hưởng từ. NB đã được điều trị thuốc và phục hồi chức năng ít nhất 3 tháng trở lên mà triêu chứng không cải thiện.

\section{Tiêu chuẩn loai trừ:}

- NB thoát vị đĩa đệm kèm biểu hiện liệt vận động rễ thần kinh tương ứng

- NB thoát vị đĩa đệm kèm rối loạn cảm giác vùng tầng sinh môn hoặc/và rối loạn đại tiểu tiện

- Nhiếm trùng, lao cột sống

- Dị ứng các thành phần thuốc: thuốc cản quang, betamethasone, lidocaine

- Từ chối tham gia nghiên cứu

Thời gian và địa điểm nghiên cứu. Nghiên cứu được thực hiện từ tháng 5/2021 tới tháng 8/2021 tại phòng mổ khoa phẩu thuật cột sống bệnh viên HN Việt Đức.

\subsection{Phương pháp nghiên cứu}

Thiết kế nghiên cứu: nghiên cứu tiến cứu mô tả cắt ngang

Cỡ mẫu: mẫu thuận tiện, trong nghiên cứu này chúng tôi tiến hành tiêm được cho 15 người bệnh

Nội dung nghiên cứu: Đối với tất cả NB, được thực hiện trên phòng mổ khoa phẫu thuật cột sống-bênhh viện HN Việt Đức. Đầu tiên tất cả NB được tiên mê nằm sấp trên bàn mổ thấu quang với gối độn mềm dưới bụng, sau đó phẫu thuật viên sẽ xác định tầng can thiệp phong bế dưới hướng dẫn của siêu âm. Bác sĩ sẽ dùng đâu dò cong với tần số 2-5 MHz, đầu tiên xác định tầng phâu thuật bằng lát cắt dọc đường giữa để xác định gai sau đốt sống $L 5$ và đường cạnh giữa để xác định mảnh sống $L 5$, qua đó đánh dấu mỏm ngang các đốt sống L3, L4 và L5 tương ứng trên da NB. Sau đó tiến hành sát trùng vùng can thiệp bằng betadin. Chải vải vô khuẩn che xung quanh vùng can thiệp, bọc đầu dò siêu âm bằng túi nilon vô trùng. Quay ngang đầu dò 90 độ xác định lỗ liên hợp dưới siêu âm lát cắt ngang là điểm dưới hình ảnh diên khớp $1 \mathrm{~cm}$. Chọc kim 25G dưới hướng dẫn của siêu âm qua lỗ liên hợp vào trong ống sống khoảng $1 \mathrm{~cm}$. Chụp Xquang đánh giá vị trí đầu kim bằng màn tăng sáng trong mổ, nếu vị trí sai thì đặt lại dưới hướng dẩn của màn tăng sáng, còn nếu đúng vị trí thì tiêm thuốc cản quang qua kim vào trong, nếu thuốc cản quang lan theo khoang ngoài màng cứng thì vị trí kim được ghi nhận là chính xác. Sau khi NB được ghi nhận kim đã ở vị trí chính xác như dự kiến, bác sĩ sẽ tiêm hỗn hợp thuốc gồm $1 \mathrm{ml}$ Lidocain $2 \%$ và $1 \mathrm{ml}$ Diprospan (7mg betamethasone) vào khoang NMC.

2.3 Chỉ số nghiên cứu và tiêu chuẩn đánh giá: Đánh giá vị trí đầu kim bằng máy tăng sáng trong mổ: đúng tầng, đúng vị trí

Độ chính xác của đâu kim: được xác định dựa vào chụp $X$ quang thấy sự tràn của thuốc cản quang qua đầu kim vào khoang ngoài màng cứng thìđược xác nhận là chính xác, thuốc lan ra ngoài lỗ liên hợp là chưa chính xác

2.4 Xử lý số liệu: số liệu nghiên cứu được xử lý theo thuật toán thống kê bằng phần mềm SPSS 18.0

\section{KẾT QUẢ NGHIÊN CỨU}

Nghiên cứu của chúng tôi thực hiện 15 mũi tiêm ở 15 NB: tiêm ngoài màng cứng qua lỗ liên hợp đốt sống 01 BN L34, 11 NB L45 và 03 NB L5S1; gồm 06 phải 09trái. Trong tổng số 15 kim thực hiện thì có 13 kim thành công như vậy tỷ lê chính xác của gây tê ngoài màng cứng qua lổ liên hợp có sự hướng dẫn của siêu âm là $86,7 \%$ được xác định bằng xquang có tiêm thuốc cản quang. Có 02 trường hợp không chính xác thì có 1 trường hợp sai tâng và 1 trường hợp đúng tầng và đúng vị trí lố liên hợp nhưng sau khi tiêm thuốc cản quang và kiểm tra dưới màn tăng sáng thì thuốc ở ngoài lỗ liên hợp; còn theo vị trí thì 1 trường hợp tầng L45 và 1 trường hợp L5S1, sau đó chúng tôi phải tiến hành thực hiện lại tiêm ngoài màng cứng dưới hướng dẫn của $X$ quang cho 02 trường hợp không chính xác này. Không có trường hợp nào xảy ra biến chứng, như đau đầu, tê, đau tăng lên, chóng mặt, dị ứng, tiêm thuốc vào mạch máu.

\section{BÀN LUÂN}

Nhìn chung, can thiệp giảm đau ngày càng đóng vai trò quan trọng trong điều trịđau do nhiều nguyên nhân gây nên và đặc biệt đối với nguyên nhân gây đau xuất phát từ cột sống. Đê̂ 
tăng độ chính xác và an toàn thì các phương pháp can thiệp giảm đau ngày nay thường được thực hiện dưới hướng dẫn của các phương tiện chẩn đoán hình ảnh [2]. Theo một số nghiển cứu, tiêm NMC không có hỗ trợ dẫn đường của chẩn đoán hình ảnh thì khả năng sai vị trí có thể lên tới $30-40 \%$ và phương pháp tiêm NMC qua lỗ liên hợp có hiệu quả giảm đau tốt hơn so với phương pháp tiêm NMC qua đường liên mỏm gai [3]. Tiêm NMC qua lỗ liên hợp đã được thực hiện dưới hướng dẫn của màn tăng sáng/cắt lớp vi tính cho kết quả tốt, chính xác, an toàn và được coi là phương pháp chuẩn trong tiêm NMC, nhưng nó có một số nhược điểm như tăng sự phơi nhiễm tia $X$ đối với NB và nhân viên y tế, chi phí cao, đầu tư máy móc đắt tiền, trang thiết bị bảo hộ nặng, nóng và không thoải mái ...,vì vậynhững nằm gần đây tiêm NMC qua lỗ liên hợp dưới hướng dẫn của siêu âmngày càng được chú ý hơn, đồng thờiphương pháp này cũng đã được chứng minh sự tin cậy và chính xác.

Trong nghiên cứu của chúng tôi, độ chính xác của tiêm NMC qua lỗ liên hợp thắt lưng dưới hướng dẫn của siêu âm sau đó được kiểm chứng bằng $x$ quang là $86,7 \%$. Hashemi đã báo cáo độ chính xác của tiêm NMC từ lỗ cựt dưới hướng dẫn của siêu âm là 95,8\%[4]. Yang báo cáo độ chính xác là $85 \%$ cho kỹ thuật tiêm NMC dưới hướng dẫn của siêu âm [5]. Còn theo Chumnanvej và $C s$ khi tiêm thắt lưng qua đường giữa, độ chính xác của đầu kim ở rễ thần kinh thắt lưng dưới hướng dẫn siêu âm là $62,8 \%$ và độ chính xác đầu kim của mỗi tâng là từ 7,14 tới 80,95\%[6].Do sự cản âm cao của xương và gián đoạn hình ảnh do hiện tượng cản âm phía sau xương nên những mốc giải phẫu của vùng cột sống lưng được nhận biết bằng siêu âm là khó khăn. Trong nghiên cứu này, chúng tôi sử dụng đường vào trong mặt phẳng cắt ngang của cột sống (axial approach) và được dẫn đường trong mặt phẳng chùm sóng siêu âm (in-plane), điều này làm cho kim được tăng sự kiểm soát chặt chẽ bởi chùm tia sóng siêu âm được phát dọc theo đầu dò của máy siêu âm. Phương pháp tiếp cận trong mặt phẳng đưa tới môt sự quan sát với thời gian thực toàn bộ kim. Trong thực tế, kim sẽ xuất hiện dưới dạng một đường thẳng tăng âm, điều này khác với kỹ thuật kim đi ngoài mặt phằng chùm sóng siêu âm (out of plane) khi đó kim chỉ dưới dạng một chấm. Các nghiên cứu cho thấy tiêm NMC qua lỗ liên hợp, kỹ thuật với kim được hướng dẫn trong mặt phẳng sóng siêu âm (in-plane) có độ chính xác cao hơn ngoài mặt phẳng sóng siêu âm (out of plane).
Gofeld[7] đã báo cáo sự chính xác của phương pháp tiêm NMC qua lỗ liên hợp dưới hướng dẩn của siêu âm, được kiểm chứng bằng chụp $x$ quang. Trong số 50 mũi tiêm được lên kế hoạch thực hiện thì có 46 mũi tiêm được thực hiện, còn 4 mũ̃i $(8 \%)$ vào L5S1 không thể thực hiển được. Trong số 46 mũi kim được thực hiện thì tất cả các kim (100\%) đều đúng tầng và nằm ở vị trí lỗ liên hợp sau khi được xác định dưới màn tăng sáng. Sau khi tiêm thuốc cản quang và kiểm tra có 42 trường hợp $(91,3 \%)$ trong lỗ liên hợp và có 4 trường hợp $(8,7 \%)$ ngoài lỗ liên hợp (rề thần kinh). Kim[8] đã cho biết trong nghiền cứu của mình số thủ thuật được tiến hành thành công là 86 trong tổng số 96 thủ thuật phong bễ rễ thần kinh đã được thực hiện, chiếm 89,6\%. Có 4 thủ thuật sai tầng cần can thiệp và 6 thủ thuật chưa chính xác vị trí lỗ liên hợp. Chúng tôi có 2 trường hợp thất bại, trong đó có 1 trường hợp sai tầng, đây là những ca đâu tiên chúng tôi thực hiện kỹ thuật, chưa có kinh nghiệm xác định tầng/vị trí đĩa đệm cần can thiệp, ngoài ra có 1 trường hợp tuy đúng tầng và vị trí lỗ liên hợp tuy nhiên khi chụp $x$ quang lên thì thuốc không vào bên trong lồ liênn hợp và ngoài màng cứng mà thuốc ở ngoài lỗ liên hợp.Theo chúng tôi, để đảm bảo chính xác đúng tầng cần can thiệp thì việc xác định chính xác mỏm ngang đốt sống $L 5$ là rất quan trọng. Để xác định đúng mỏm ngang đốt sống $L 5$ dưới siêu âm, chúng ta cần xác định chính xác gai sau và/hoặc mảnh sống L5 bằng cách đặt đầu dò siêu âm dọc theo đường giữa lưng và đường cạnh giữa, sau đó sẽ thấy được gai sau L5 to nhất, dưới cùng, hoặc sẽ thấy mảnh sống $L 5$ dưới cùng và khác biệt với cung sau S1. Chúng tôi chỉ có một trường hợp không tiêm được ngoài màng cứng mà thuốc lan ra ngoài lỗ liên hợp ở vị trí L5S1, đây là trường hợp vướng xương chậu làm kim không đủ hướng chếch vào trong lỗ liên hợp, để khắc phục trường hợp này theo các tác giả trên thế giới sử dụng đường vào chếch hoặc uốn cong đầu kim. Trong nghiên cứu của chúng tôi không có biến chứng nào được ghi nhận, NB sau thủ thuật được lưu lại trong bệnh viện ít nhất một giờ. Qua nghiên cứu này chúng tổi thây rằng để giảm tỷ lệ biến chứng như thủng màng cứng, tổn thươning rễ thần kinh, chúng tôi dùng kim chọc tủy sống với đường kính $25 \mathrm{G}$ nhỏ hơn so các nghiên cứu của các tác giả trên thế giới, về kỹ thuật chúng tôi dùng kỹ thuật của Galiano[9] để xác định lỗ liên hợp, cùng với sau khi kim bắt đầu qua dây chằng vàng thì sẽ tiếp tục đâm kim tiếp xuống khoảng $1 \mathrm{~cm}$, sau đó phải hút ra khi không có máu hoặc 
dịch trong ra thì mới tiến hành tiêm thuốc các bước tiếp theo.

\section{KẾT LUÂN}

Tiêm NMC dưới hướng dẫn của siêu âm là kỹ thuật an toàn và khả thi trong thực hành lâm sàng giúp nâng cao trong công tác điêu trị và chẩn đoán, nhưng không làm nhân viên y tế và người bênh phải phơi nhiễm với tia $X$.

Tuy nhiên, số lương NB của nghiên cứu còn ít, đòi hỏi phải làm tiếp để đánh giá độ an toàn, chính xác và hiệu quả của phương pháp.

\section{TÀI LIÊU THAM KHẢO}

1. S. Datta, "Systematic review of therapeutic lumbar transforaminal epidural steroid injections," Accessed: Aug. 12, 2021. [Online]. Available: www.painphysicianjournal.com.

2. T. Grau, R. W. Leipold, S. Fatehi, E. Martin, and J. Motsch, "Real-time ultrasonic observation of combined spinal-epidural anaesthesia," in European Journal of Anaesthesiology, Jan. 2004, vol. 21, no. 1, pp. 25-31, doi: 10.1017/S026502150400105X.

3. J. H. Levin, R. Wetzel, and M. W. Smuck, "The Importance of Image Guidance during Epidural Injections: Rates of Incorrect Needle Placement during Non-Image Guided Epidural Injections," ] Spine, vol. 1, no. 2, 2012, doi: 10.4172/21657939.1000113.

4. M. Hashemi, P. Dadkhah, M. Taheri, S. M.
Haji, S. Abootorabi, and B. Naderi-Nabi, "Ultrasound-Guided Lumbar Transforaminal Epidural Injections; A Single Center Fluoroscopic Validation Study," Bull Emerg Trauma, vol. 7, no. 3, pp. 251-255, 2019, doi: 10.29252/beat-070307.

5. Y. G et al. "Ultrasound-guided Versus Fluoroscopy-controlled Lumbar Transforaminal Epidural Injections: A Prospective Randomized Clinical Trial," Clin. J. Pain, vol. 32, no. 2, pp. 103108, 2016, doi: 10.1097/AJP.0000000000000237.

6. V. K. Chumnanvej, Sorayouth, Narongdet Wetchagama, "Accuracy of needle-tip localization by ultrasound guidance lumbar selective nerve root block: a prospective clinical study of 78 lumbar nerve roots block - PubMed." https://pubmed.ncbi.nlm.nih.gov/22295731/ (accessed Aug. 17, 2021)

7. M. Gofeld, S. J. Bristow, S. C. Chiu, C. K. McQueen, and L. Bollag, "Ultrasound-guided lumbar transforaminal injections: Feasibility and validation study," Spine (Phila. Pa. 1976)., vol. 37, no. 9, pp. 808-812, Apr. 2012, doi: 10.1097/BRS.0B013E3182340096.

8. D. Kim, D. Choi, C. Kim, J. Kim, and Y. Choi, "Transverse Process and Needles of Medial Branch Block to Facet Joint as Landmarks for UltrasoundGuided Selective Nerve Root Block," Clin. Orthop. Surg., vol. 5, no. 1, pp. 44-48, Feb. 2013, doi: 10.4055/CIOS.2013.5.1.44.

9. K. Galiano et al., "Real-time Sonographic Imaging for Periradicular Injections in the Lumbar Spine," J. Ultrasound Med., vol. 24, no. 1, pp. 3338, Jan. 2005, doi: 10.7863/JUM.2005.24.1.33.

\section{KHẢO SÁT KIẾN THỨC, THÁI ĐÔ VÀ THỰC HÀNH CỦA THAI PHU CÓ TUỔI THAI TỪ 36 TUẦ ĐẾN 37 TUẦN 6 NGÀY V̂̂ TÂM SOÁT NHIỄM STREPTOCOCCUS NHÓM B TẠI BÊ̂NH VIÊ̂N TỪ DŨ}

\section{TÓM TẮT}

Đăt vấn đề: Trong các tác nhân gây các bệnh nhiễm trùng ở trẻ sơ sinh, GBS là một trong các tác nhân phổ biến nhất, thường gây nhiếm trùng sơ sinh sớm và có thể dẫn tới tử vong. Việc thực hiện xét nghiệm tầm soát GBS sớm trong thai kì được chứng minh là làm giảm tỉ suất bệnh ở trẻ, tuy nhiên thực hành xét nghiệm này còn chưa thật phổ biến và trở thành vấn đề ngày càng được quan tâm [3]. Mục tiêu: Xác định tỉ lệ thai phụ ở tuổi thai từ 36 tuần đển 37 tuần 6 ngày có kiến thức đúng, thái độ đúng và

${ }^{1}$ Đại họ Y Dướ TPHCM

${ }^{2}$ Bềnh viền Tữ Dũ

Chịu trách nhiệm chính: Bùi Chí Thương

Email: buichithuong@ump.edu.vn

Ngày nhận bài: 10.8.2021

Ngày phản biên khoa hoc: 4.10 .2021

Ngày duyệt bài: 13.10.2021 Phạm Thị Bảo Châu1, Bùi Chí Thương1,
Phạm Phương Duy², Hồ Huỳnh Nhung

thực hành đúng về xét nghiệm tầm soát Streptococcus nhóm $B$ tai bênh viên Tữ Dũ. Phương pháp: Nghiên cứu cắt ngang trên 385 sản phụ tuổi thai từ 36 tuần đến 37 tuần 6 ngày khám thai tai Bênh viên Từ Dũ từ tháng 11/2020 đến tháng 3/2021. Kết quả: Có $27,5 \%$ sản phu có kiến thức đối với xét nghiêm tầm soát Streptococcus nhóm $B$, tỉ lệ này liên quan đến việc thai phu đã được thông tin về xét nghiêm này trước đó mà không liên quan đến các yếu tổ dịch tễ hay sản khoa khác. Măc dù vậy, gân phân nửa sản phụ khoảng $42,6 \%$ ủng hộ cho việc tầm soát thường qui đối với xét nghiệm tầm soát Streptococcus nhóm B. Nghiên cứu cũng ghi nhận có $6,8 \%$ sản phụ đã thực hiện xét nghiệm tai thời điểm phỏng vấn, đồng thời 6 tuần sau phỏng vẩn, chúng tôi ghi nhận số thai phụ thực hiện xét nghiệm này trong thai kì đến khi chưển da tại bênh viên Từ Dũ là 13\%. Kết luânn: Tỉ lệ sản phụ có kiến thức đối với xét nghiệm tầm soát Streptococcus nhóm $\mathrm{B}$ là 27,5\%. Phần lớn sản phụ chưa được thông tin, không có kiến thức đúng về xét nghiệm khi đến 